\title{
Risk Acceptance in the Furniture Sector: Analysis of Acceptance Level and Relevant Influence Factors
}

\author{
M. A. Rodrigues, P. M. Arezes \& C. P. Leão
}

\begin{abstract}
Risk acceptance has been broadly discussed in relation to hazardous risk activities and/or technologies. A better understanding of risk acceptance in occupational settings is also important; however, studies on this topic are scarce. It seems important to understand the level of risk that stakeholders consider sufficiently low, how stakeholders form their opinion about risk, and why they adopt a certain attitude toward risk. Accordingly, the aim of this study is to examine risk acceptance in regard to occupational accidents in furniture industries. The safety climate analysis was conducted through the application of the Safety Climate in Wood Industries questionnaire. Judgments about risk acceptance, trust, risk perception, benefit perception, emotions, and moral values were measured. Several models were tested to explain occupational risk acceptance. The results showed that the level of risk acceptance decreased as the risk level increased. High-risk and death scenarios were assessed as unacceptable. Risk perception, emotions, and trust had an important influence on risk acceptance. Safety climate was correlated with risk acceptance and other variables that influence risk acceptance. These results are important for the risk assessment process in terms of defining risk acceptance criteria and strategies to reduce risks.
\end{abstract}

\section{Key Words}

acceptance model, risk, occupational accidents, safety climate

\section{INTRODUCTION}

Risk acceptance is a complex matter that has been broadly discussed over the past decades. Several studies on the risk acceptance of an activity or technology within society have analyzed the concept and the factors that influence it (for a review, see Boholm 1998; Huijts et al. 2012). Huijts NMA, Molina EJE, and Steg L. 2012. Psychological factors influencing sustainable energy technology acceptance: A review-based comprehensive framework. Renew Sust Energ Rev 16(1):525-31). These studies have provided insights into how people form their opinion of public risks. Furthermore, they have shown that a lack of public support for a technology or activity can reduce its viability and that risk acceptance is an important predictor of risk behaviors (Bronfman et al. 2012; Huijts et al. 2012).

Studies have made advances concerning hazardous technologies and activities. However, the analysis of risk acceptance is also fundamental for occupational settings, as highlighted by the fact that occupational accidents lead the panorama of world accidents (Kjellén and Sklet 1995; Harms-Ringdahl 2001). In this context, an effective decision- 
making process is of paramount importance, and all information that can increase the effectiveness of the process is useful, particularly judgments about the stakeholders' risk acceptance. In fact, these judgments play an important role in the risk assessment process, particularly in what concerns the acceptance criteria definitions (ISO 31000:2009). Therefore, it is important to understand the level of risk that stakeholders consider to be sufficiently low, how stakeholders form their opinion about a given risk, and why they adopt a certain attitude toward risk. Furthermore, it is essential to analyze whether the noted factors that influence risk acceptance for hazardous technologies and activities are at play for occupational risks and to understand the how and the degree of the impact of these factors on the level of risk acceptance.

Previous studies in other areas have identified several important factors that can influence risk acceptance. Risk perception, benefit perception, and trust play an important role in risk acceptance (Siegrist 1999, 2000; Siegrist et al. 2000, 2005; Bronfman et al. 2008, 2009, 2012; Huang et al. 2010, 2013; Ji et al. 2011). However, other factors, such as emotions, can influence risk acceptance via risk perception (Roeser 2006; Young et al. 2015). Furthermore, several studies have indicated that risk acceptance and perceptions vary by social group (Boholm 1998; Kouabenan 2009; Tingley et al. 2010; Remoundou et al. 2014) because of cultural and contextual differences. Therefore, and using the same logic, risk acceptance may also vary by organization because of differences in safety culture or safety climate.

In view of the above, knowledge about how people think about and respond to risk in occupational settings can be useful for managers and decision-makers. Such information may (i) provide relevant insights to help organizations define acceptance criteria to be included in risk assessment methodologies, (ii) aid in anticipating and understanding responses to hazards, such as safety behaviors, (iii) improve the design of strategies to reduce risks, and (iv) provide information about risk (Slovic 1987; Huijts et al. 2012; Remoundou et al. 2014).

In this context, the present study examined risk acceptance in regards to occupational risks in the furniture sector. The study analyzed the level of risk acceptance and some of the key factors that, directly and indirectly, play an important role in occupational accident risk acceptance. The following factors were considered: risk and benefit perceptions, trust, emotions, and companies' safety climate. Some moral values that are important to consider in the risk acceptance criteria formulation were also analyzed.

\section{METHODOLOGY}

\section{Samples}

The results of the study were based on data that were collected from 14 Portuguese furniture companies. The analyzed companies varied in size from micro- (fewer than 10 employees) to small- (from 10 to 50 employees) to medium- (from 50 to 250 employees) sized companies.

The companies comprised a total of 517 workers who performed manual labor, of which 403 participated in the study. Most of the participants were males (86.6\%), and their mean age was 39.5 years old ( $S D=10.1$; interval range $18-63$ years old). Workers had been employed by their companies for an average of 10.5 years ( $S D=7.3$; interval range $0-37$ years) and had been engaged in manual labor for an average of 17.5 years ( $S D=12.1$; interval range $1-50$ years). Shown in Table 1 are detailed data concerning the sample for each of the studied companies. 
Table 1. Workers' characterisation for each company.

\begin{tabular}{|c|c|c|c|c|c|c|c|c|}
\hline \multirow[b]{2}{*}{ Company } & \multirow{2}{*}{$\begin{array}{l}\text { Number of } \\
\text { workers }\end{array}$} & \multirow[b]{2}{*}{ Sample } & \multicolumn{2}{|c|}{ Age } & \multicolumn{2}{|c|}{$\begin{array}{l}\text { Years in } \\
\text { current } \\
\text { company }\end{array}$} & \multicolumn{2}{|c|}{$\begin{array}{c}\text { Years of } \\
\text { activity }\end{array}$} \\
\hline & & & M & $\mathrm{SD}$ & M & SD & M & SD \\
\hline A & 5 & 5 & 50.8 & 6.1 & 19.8 & 3.0 & 27.2 & 7.6 \\
\hline B & 53 & 42 & 39.4 & 10.1 & 12.5 & 5.9 & 18.8 & 10.6 \\
\hline C & 104 & 58 & 42.7 & 8.4 & 11.2 & 6.6 & 19.3 & 11.6 \\
\hline D & 20 & 16 & 33.6 & 8.8 & 5.7 & 4.9 & 15.1 & 7.8 \\
\hline E & 5 & 5 & 38.2 & 9.0 & 3.4 & 1.3 & 19.6 & 10.0 \\
\hline $\mathrm{F}$ & 7 & 7 & 38.9 & 5.3 & 7.0 & 2.9 & 17.4 & 6.5 \\
\hline G & 17 & 12 & 42.8 & 11.7 & 19.8 & 7.9 & 25.2 & 14.0 \\
\hline $\mathrm{H}$ & 85 & 75 & 37.3 & 10.9 & 8.8 & 5.7 & 17.0 & 12.5 \\
\hline I & 15 & 12 & 46.0 & 9.7 & 18.7 & 7.1 & 27.0 & 12.9 \\
\hline $\mathrm{J}$ & 71 & 68 & 37.6 & 11.0 & 8.7 & 6.4 & 15.4 & 13.5 \\
\hline K & 12 & 11 & 38.1 & 11.0 & 15.6 & 7.4 & 13.1 & 10.8 \\
\hline $\mathrm{L}$ & 101 & 66 & 40.7 & 8.7 & 9.2 & 8.2 & 16.1 & 11.5 \\
\hline M & 11 & 7 & 35.7 & 8.2 & 11.7 & 9.0 & 8.5 & 5.5 \\
\hline $\mathrm{N}$ & 10 & 7 & 40.7 & 6.7 & 12.9 & 7.1 & 16.7 & 10.7 \\
\hline
\end{tabular}

M: Means; SD: standard deviation.

The study also involved 14 employers (one for each company) and nine supervisors. The average age was 43.9 years old ( $S D=13.9$; interval range $22-86$ years). In general, they had worked with their companies for an average of 17.6 years $(S D=9.2$; interval range $1-35$ years) and had engaged in such activity for an average of 25.3 years ( $S D=17.4$; interval range $1-75$ years).

\section{Instruments}

\section{Safety climate analysis}

Safety climate was used in this study as an indicator of safety culture, as indicated by several authors (Flin et al. 2000; Tharaldsen et al. 2008; Høivik et al. 2009, to analyze its influence on risk acceptance.

A multilevel analysis of safety climate was performed using the Safety Climate in Wood Industries (SCWI) questionnaire. The SCWI was developed to measure the safety climate in the furniture industries, reflecting the level of safety conditions, by using a multilevel structure (Rodrigues et al., in press). This instrument includes a total of 34 items that are distributed into three levels of analysis (i.e., organizational, group, and individual levels). The items were based on the works of Zohar and Luria (2005) and Tharaldsen et al. (2008). Specific items related with the sector were also considered in SCWI. The questionnaire development process, testing, and validation are described in more detail elsewhere (Rodrigues et al. 2013, in press). The process of validation was performed through a multilevel exploratory factor analysis using the procedure 
presented in van de Vijver and Poortinga (2002) and Reise et al. (2005), which was derived from the steps proposed by Muthén (1994), as described by the authors in Rodrigues et al. (in press).

Organizational level was measured with 13 items concerning management investment in safety issues, continuous improvement of safety systems, and safety communication. Since the validation of the scales is described in Rodrigues et al. (in press); the present study reports only the Cronbach's alpha values of this scale, which was 0.9 and can be regarded as acceptable (>0.7). Group level was measured with 12 items. At this level, workers were asked about supervisor concerns regarding workers' safety practices, involvement in safety issues and effort in regards to rules compliance and safety protection use. This scale had an Cronbach's alpha of 0.8. Finally, at the individual level, 9 items measured workers' commitment to safety. The Cronbach's alpha of this scale was 0.7. The level of agreement with each item was assessed using a 5 -point Likert scale that ranged from " $1=$ Strongly disagree" to " $5=$ Strongly agree."

\section{Analysis of risk acceptance}

Judgments about risk acceptance were measured through a questionnaire that includes five other variables, namely: trust, risk perception, benefit perception, emotions, and values. Three versions of the questionnaire were constructed, one for each of the following groups in the analysis: workers, employers, and supervisors.

Two different parts comprised the questionnaire. The first one was related with the respondents' characterization. The following respondent characteristics were measured: age, gender, department/sector, professional activity, number of years working at the company, number of years at the mentioned professional activity, and previous involvement in work accidents. For employers, only questions related to age, gender, and any contact with an occupational accident were measured. Then, in the second part, the analysis variables were measured (on 5-point Likert scales) based on previous research studies in various areas (Siegrist 2000; Tharaldsen et al. 2008; Bronfman et al. 2012). The scales that were utilized are presented in Table 2.

Table 2. Scales utilized for each variable.

\begin{tabular}{lll}
\hline Variable & \multicolumn{2}{c}{ Scale endpoints } \\
\hline Acceptance & $1=$ Unacceptable & $5=$ Acceptable \\
Trust & $1=$ No trust at all & $5=$ High trust \\
Risk Perception & $1=$ Not risky at all & $5=$ Very risky \\
Benefit Perception & $1=$ Not beneficial at all & $5=$ Very beneficial \\
Moral Values & $1=$ Strongly disagree & $5=$ Strongly agree \\
Emotions & $1=$ Not worried at all & $5=$ Very worried \\
\hline
\end{tabular}

The questions about risk acceptance, risk perceptions, and emotions were based on scenarios (for short item descriptions, SA1-SA6, SB1-SB5, and SC; Table 3). These scenarios were constructed based on accident frequencies, days lost for each accident type (accident statistics for the year 2008 for the wood and mattresses manufacturing) and the companies' safety conditions analyses. The accident data were collected by the Portuguese Office of Strategy and Planning (GEP) and supplied for the current study. These statistics were grouped according to Eurostat (2012) classification. 
Table 3. Risk scenarios and the referent risk level computed.

\begin{tabular}{|c|c|c|}
\hline \multirow[b]{2}{*}{ Code } & Scenario description & \multirow{2}{*}{$\begin{array}{c}\text { Risk Level (RL) } \\
\text { computed }\end{array}$} \\
\hline & In a company with 100 workers... & \\
\hline SA1 & $\begin{array}{l}1 \text { worker suffering } 1 \text { cut due to the use of cutting } \\
\text { saws without protection every } 72 \text { years, getting } \\
\text { incapacitated for work for } 1 \text { year }\end{array}$ & 0.05 \\
\hline SA2 & $\begin{array}{l}1 \text { worker suffering } 1 \text { cut due to the use of cutting } \\
\text { saws without protection every } 10 \text { years, getting } \\
\text { incapacitated for work for } 6 \text { months }\end{array}$ & 0.18 \\
\hline SA3 & $\begin{array}{l}1 \text { worker suffering } 1 \text { cut due to the use of cutting } \\
\text { saws without protection every } 2 \text { years, getting } \\
\text { incapacitated for work for } 4 \text { months } 1 \text { worker } \\
\text { suffering }\end{array}$ & 0.60 \\
\hline SA4 & $\begin{array}{l}1 \text { cut due to the use of cutting saws without } \\
\text { protection every year, getting incapacitated for } \\
\text { work for } 2 \text { months }\end{array}$ & 0.60 \\
\hline SA5 & $\begin{array}{l}1 \text { worker suffering } 1 \text { cut due to the use of cutting } \\
\text { saws without protection every } 4 \text { months, getting } \\
\text { incapacitated for work for } 1 \text { month }\end{array}$ & 0.90 \\
\hline SA6 & $\begin{array}{l}1 \text { worker suffering } 1 \text { cut due to the use of cutting } \\
\text { saws without protection every } 4 \text { months, getting } \\
\text { incapacitated for work for } 1 \text { day }\end{array}$ & 0.03 \\
\hline SB1 & $\begin{array}{l}1 \text { worker suffering } 1 \text { a musculoskeletal disorder } \\
\text { every } 33 \text { years, getting incapacitated for work for } \\
6 \text { months }\end{array}$ & 0.05 \\
\hline SB2 & $\begin{array}{l}1 \text { worker suffering } 1 \text { a musculoskeletal disorder } \\
\text { every } 2 \text { years, getting incapacitated for work for } 4 \\
\text { months }\end{array}$ & 0.60 \\
\hline SB3 & $\begin{array}{l}1 \text { worker suffering } 1 \text { a musculoskeletal disorder } \\
\text { every year, getting incapacitated for work for } 2 \\
\text { months }\end{array}$ & 0.60 \\
\hline SB4 & $\begin{array}{l}1 \text { worker suffering } 1 \text { a musculoskeletal disorder } \\
\text { every } 5 \text { months, getting incapacitated for work } \\
\text { for } 1 \text { month }\end{array}$ & 0.72 \\
\hline SB5 & $\begin{array}{l}1 \text { worker suffering } 1 \text { a musculoskeletal disorder } \\
\text { every month, getting incapacitated for work for } \\
1 \text { day }\end{array}$ & 0.02 \\
\hline & In 36878 workers... & \\
\hline $\mathrm{SC}$ & 1 dead by year & 0.20 \\
\hline
\end{tabular}

The "Contact with sharp, pointed, rough, coarse material agent" and "Physical or mental stress" were the two most frequent modes of injury in this sector. For each of these modes of injury, several scenarios were created with consideration of the following criteria:

- the most frequent and the worst situations;

- a mid risk situation;

- scenarios with the same risk level. 
To facilitate the respondents' judgment, the scenario for each mode of injury was based on the most frequent risk identified in the analyzed companies (i.e., cut with a saw and a musculoskeletal disorder [MSDs]). A scenario that corresponded to a death by year was also created (SC). According to GEP data, no death accidents occurred in this sub-sector in 2008; however, one fatal accident occurred in both 2006 and 2007.

To analyze benefits perceptions, two groups of questions (each with three items) were included. The first group referred to benefits for the employer (BE) (e.g., higher production), and the second group evaluated benefits for the worker (BW) (e.g., ease in performing tasks and higher salary). The included items were related to exposure to the hazards associated with the most frequent risks in the sector, as follows: "Operate with saws without protection" (BE1 and BW1), "Perform repetitive tasks for long periods" (BE2 and BW2), and "Perform tasks of manual material handling" (BE3 and BW3). An example of the corresponding benefits was included in the questions.

Trust was measured at various levels, that is, management decisions on risk control, the actuation of Occupational, Safety and Health $(\mathrm{OSH})$ practitioners on risk control and supervisor actuation to enforce the rules and safety procedures. This group of questions differs across the questionnaire versions. Supervisors and employers do not respond to the question that refers to them.

Respondents also reported important values in risk acceptance. Three moral values were measured, as follows: equity, equality, and justice. Equity was analyzed according to concerns related to the need for a limit above which no individual should be exposed. Equality was related to the need for the same upper risk threshold to be applied to all enterprises of the sector. Finally, justice considered the unfairness of exposing a worker to very high risk, regardless of the associated benefits.

The validity and reliability of the instrument is described in more detail elsewhere (Rodrigues et al. 2014). Exploratory factor analysis was performed and to test the internal consistency of the identified factors Cronbach's alpha were calculated. Since the validation of the scales is described in Rodrigues et al. (2014), the present study reports only the in Cronbach's alpha values of this scale, which ranged from 0.8 to 0.9 and can be regarded as acceptable ( $>0.7)$. The item related to the worst scenario for MSDs risk acceptance was eliminated in the validation process, because it was not related to any of the considered factors. Consequently, the corresponding scenarios included in risk perception and emotions were also excluded.

\section{Procedures}

The instruments were applied to all workers, employers, and supervisors of the 14 furniture companies. The questionnaires were personally delivered by researchers and then completed during working hours or at the end of the work shift (at the company or at home). Participants were notified that their participation was voluntary and confidential. They were also informed that if they experienced any difficulty in answering any question, they could request assistance from the researchers or company managers.

\section{Data analysis}

The score of the total safety climate and of each safety climate scale was determined by adding the level of respondents' agreement with each item included in the scale. Bivariate correlation 
analysis was performed using the statistical software package IBM SPSS Statistics version 20 to analyze the correlation between safety climate and the other variables in analysis.

The Risk Level ( $\mathrm{RL}$ ) represents the risk of one worker suffer an accident with a specific severity in 1 year. It was estimated for each acceptance scenario (Table 3), taking into account the accident frequency and its severity (number of lost work days) as follows:

$$
\frac{F \times D L}{100}
$$

where $F$ corresponds to the accident frequency and $D L$ corresponds to the number of days lost. The accident frequency was standardized for 1 year.

To test which model better explains risk acceptance in occupational settings, a path analysis was performed using IBM SPSS Amos version 19. The goodness of fit of the models was evaluated. In accordance with Kline (2010), the Chi-squared test $\left(\chi^{2}\right)$, Comparative Fit Index (CFI), Root Mean Square Error of Approximation (RMSEA), and Standardized Root Mean Square Residual (SRMR) were analyzed.

RESULTS AND DISCUSSION

\section{Analysis of the Risk Acceptance Level}

Presented in Figure 1 is the analysis of workers' risk acceptance level for each of the scenarios, considering the risk level computed. An "A" was introduced before each scenario for risk acceptance in order to differentiate them from those related with emotions and risk perception. The risk level was computed while accounting for the frequency of the accident occurrence and the number of days lost, as presented in Table 3. In accordance with Miguel (2012), for the scenario of one fatality was considered a loss of 7500 workdays. This number of lost workdays is also used by the Portuguese authorities to account for one death in statistical terms. 


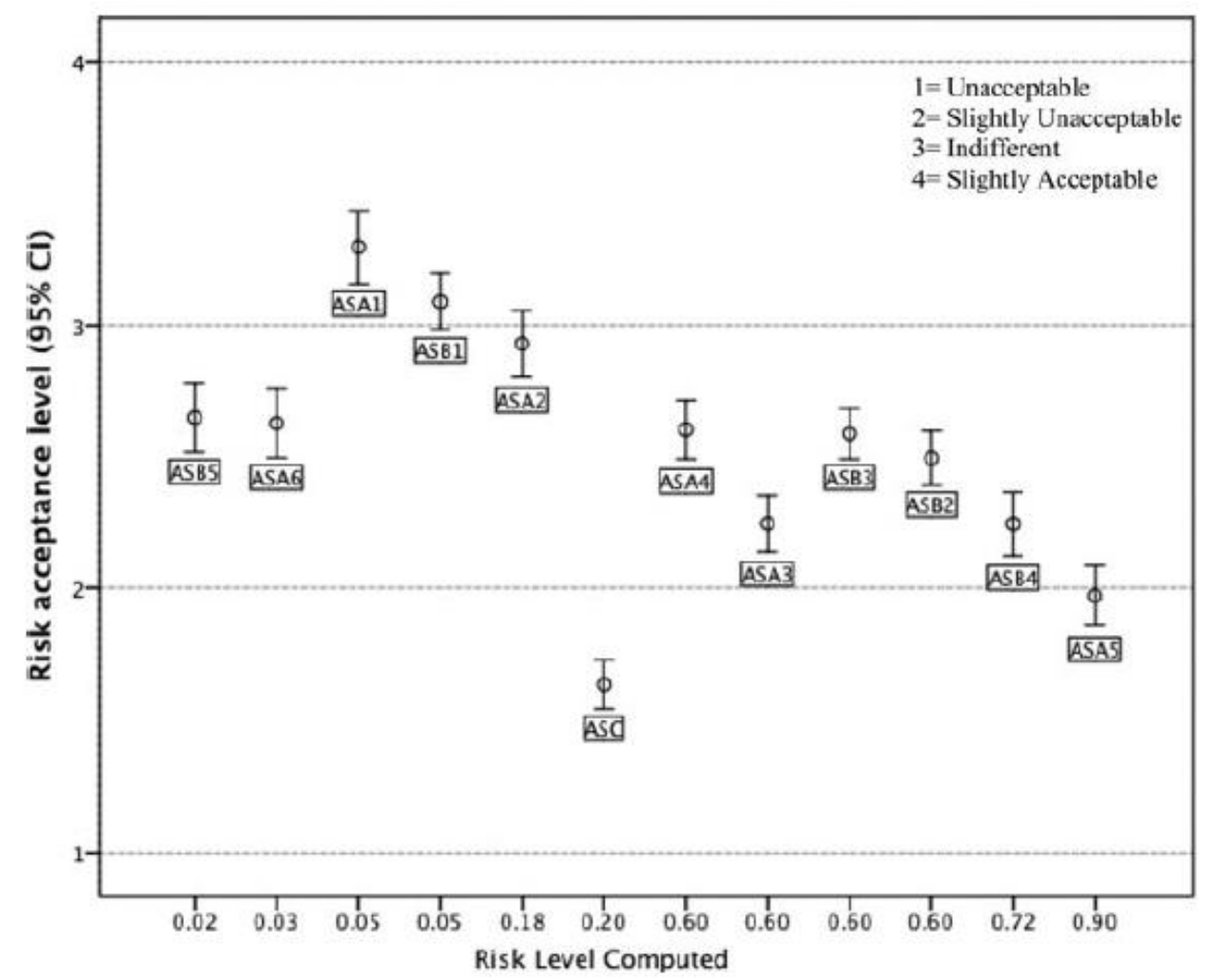

Figure 1. Workers' risk acceptance level by risk level computed for each scenario.

In general, the results show that the level of risk acceptance decreased as the risk level of the scenario increased. Accordingly, workers evaluated higher risk situations as unacceptable and lower risk situations as more acceptable. However, some exceptions were observed. One of these exceptions, perhaps the most obvious, refers to the death scenario. Although it is not the worst-case scenario that was mathematically created (RL $=0.20$ ), the death scenario obtained the highest level of unacceptability, possibly due to feelings of distrust, fear, and vulnerability associated with a fatality (Cameron and Raman 2005).

Another interesting result regards four scenarios with the same risk level (i.e., $\mathrm{RL}=0.60$ ). These scenarios differ in severity and frequency for both modes of injury (ASA3 and ASB2 have higher severity). According to the results, when the severity was higher, the level of acceptance tended to be lower (ASA3-ASA $4 t(396)=8.45, p<.001$; ASB2-ASB3 $t(396)=2.30, p<.05)$. These findings were expected since previous works observed that risk perception tends to increase as the severity of the scenario increase (Young et al. 2015). Furthermore, the specific scenarios created may also had an influence on the obtained results (Wogalter et al. 1999; Rundmo et al. 2011). According to Rundmo et al. (2011), severity of the consequences has influence on the level of risk acceptance; however, in areas where the severity of the consequences is moderated or small, the importance of the consequences is lower. The current study showed that in fact severity is an important factor for risk acceptance level, but its effect was also high for moderated risks and not only for high risks as previously observed for the death scenario where the risk acceptance level was low.

The results obtained for the lower risk scenarios were also interesting. In the first scenarios, where $\mathrm{RL}=0.02$ (ASB5) and $\mathrm{RL}=0.03$ (ASA6), the level of risk acceptance was lower than that in the scenarios ASA1, ASA2, and ASB1, which had higher risk levels. These scenarios were referring to accidents that lead to one lost workday (small 
severity), but where the frequency of the event is very high. For these scenarios, accident frequency appears to have higher influence on risk acceptance level than severity, because in another way the level of risk acceptance would have been higher, as this is the scenario with lower severity. This, in accordance with Rundmo et al. (2011), can be due to the low effect of severity when severity of the consequences is small. In view of this, the results suggest that the influence of accident frequency is observed in scenarios with small severity of consequences. Workers are less likely to accept scenarios that they see as being highly likely to occur. However, when severity is high the influence of frequency appears to disappear and the judgments about risk acceptance are dependent on accident severity, perhaps because of the feeling of fear and/or vulnerability (Cameron and Raman 2005). The differences between both cut (ASA3 and ASA4) and MSDs (ASB2 and ASB3) scenarios were also analyzed. When the severity was higher, the differences between the two modes of injury were significant, with a lower risk acceptance level for the cut scenarios (ASA3 and ASB2 $\mathrm{t}(396)=4.38, p<.001$ ). However, for scenarios with lower severity, there were no significant differences between the judgments for the two scenarios when the risk level was the same (ASA4 and SB3 $t(396)=0.27, p>.05$ ). These results suggest that workers had a similar level of risk acceptance for lower risk levels. However, for high risks, they tended to have different judgments for each mode of injury. This result may be related to the differences in the physical damage (Huang et al. 2010), where cuts are seen to be more negative, being in the furniture companies frequently related with permanent injuries (amputations).

Presented in Table 4 is the summary of workers', employers', and supervisors' risk acceptance levels. In general, supervisors evaluated the scenarios as more unacceptable. For both cut and death scenarios, employers evaluated risk as more acceptable. For example, for the scenario ASA1, on average, the supervisors' risk acceptance was lower (2.6) than that of employers (3.4) and workers (3.3). For the death scenario (ASC), the differences between the three groups became more obvious. Specifically, supervisors evaluated risk as unacceptable (1.3), whereas employers evaluated risk as indifferent (2.5). Supervisors' lower levels of risk acceptance could be due to their responsibility in interpreting and implementing company procedures because their practice is a powerful or proximal antecedent of workers' behavior and in compliance with safety rules (Zohar and Luria 2005). Therefore, supervisors work to avoid accidents. Further, they may be more intolerant of accident occurrence. However, the employers' perspectives may be more related to costs of accident prevention; thus, they may be more tolerant of risks. 
Table 4. Workers', employers,' and supervisors' risk acceptance levels.

\begin{tabular}{|c|c|c|c|c|c|c|}
\hline & \multicolumn{2}{|c|}{ Workers } & \multicolumn{2}{|c|}{ Employers } & \multicolumn{2}{|c|}{ Supervisors } \\
\hline & M & SD & M & SD & $\mathrm{M}$ & SD \\
\hline ASA1 & 3.3 & 1.4 & 3.4 & 1.6 & 2.6 & 1.3 \\
\hline ASA2 & 2.9 & 1.3 & 3.2 & 1.6 & 2.6 & 1.3 \\
\hline ASA3 & 2.6 & 1.1 & 2.5 & 1.1 & 2.1 & 0.9 \\
\hline ASA4 & 2.2 & 1.1 & 2.4 & 1.2 & 2.1 & 0.9 \\
\hline ASA5 & 2.0 & 1.2 & 2.2 & 1.3 & 1.8 & 1.0 \\
\hline ASA6 & 2.6 & 1.3 & 3.1 & 1.6 & 2.4 & 1.2 \\
\hline ASB1 & 3.1 & 1.1 & 3.4 & 1.5 & 3.0 & 1.0 \\
\hline ASB2 & 2.6 & 1.0 & 2.4 & 1.2 & 2.2 & 0.7 \\
\hline ASB3 & 2.5 & 1.1 & 1.7 & 1.2 & 2.0 & 0.7 \\
\hline ASB4 & 2.2 & 1.2 & 1.5 & 0.9 & 1.7 & 0.9 \\
\hline ASB5 & 2.7 & 1.3 & 1.6 & 0.9 & 1.9 & 0.8 \\
\hline ASC & 1.6 & 0.9 & 2.5 & 1.7 & 1.3 & 0.5 \\
\hline $\mathrm{n}$ & \multicolumn{2}{|c|}{397} & \multicolumn{2}{|c|}{14} & \multicolumn{2}{|c|}{9} \\
\hline
\end{tabular}

Influence of Risk and Benefit Perception, Trust, and Emotions on Risk Acceptance

Shown in Table S1 (see the online supplementary information [SI]) are the correlations among each acceptance (A) scenario with risk perception (RP), benefit perception (BP), emotions (E), and trust (T). The results showed that risk perception, emotions, and trust in management decisions on risk control (T1) were all significantly correlated with risk acceptance $(p<.001$, except $p<.05$ for the scenario ASC). Trust in actuation of OSH practitioners on risk control (T2) and trust in supervisor actuation to enforce the rules and safety procedure (T3) were correlated with all scenarios of risk acceptance $(p<.001)$, except the scenario ASC (i.e., the death scenario). Positive correlations were found for trust, and negative correlations were found for risk perception and emotions.

The results presented in Table $\mathrm{S} 1$ also show that only some acceptance scenarios were correlated with benefits, considering both benefits for workers (BW1, BW2, and BW3) and benefits for employers (BE1, BE2, and BE3) (Table 4). This may be related to the type of benefits considered and the scenarios in the analysis. In occupational environments, the benefits can be viewed from the perspective of workers (a better salary) and the perspective of employers (an increased production rate). The results showed that benefits were significantly correlated with risk acceptance only for the employers. Of note, in most of the situations, the correlation was positive. However, in some cases, negative correlations were identified. These results may be due to the severity of the damage related to the scenario, that is, difficulties in identifying benefits for scenarios with high severity (e.g., ASB1, for which severity is 6 months). However, for scenarios with low severity, the risk acceptance was higher when the employers' benefit perception was higher (positive correlation).

To better understand these results and to analyze the influence of the variables on risk acceptance, several models for each of the scenarios were confirmed through a path analysis. Presented in Figure 2 is the model with the best fit indices for most of the scenarios analyzed (Table S2, SI). None of the death scenario models demonstrated good fit indices. 


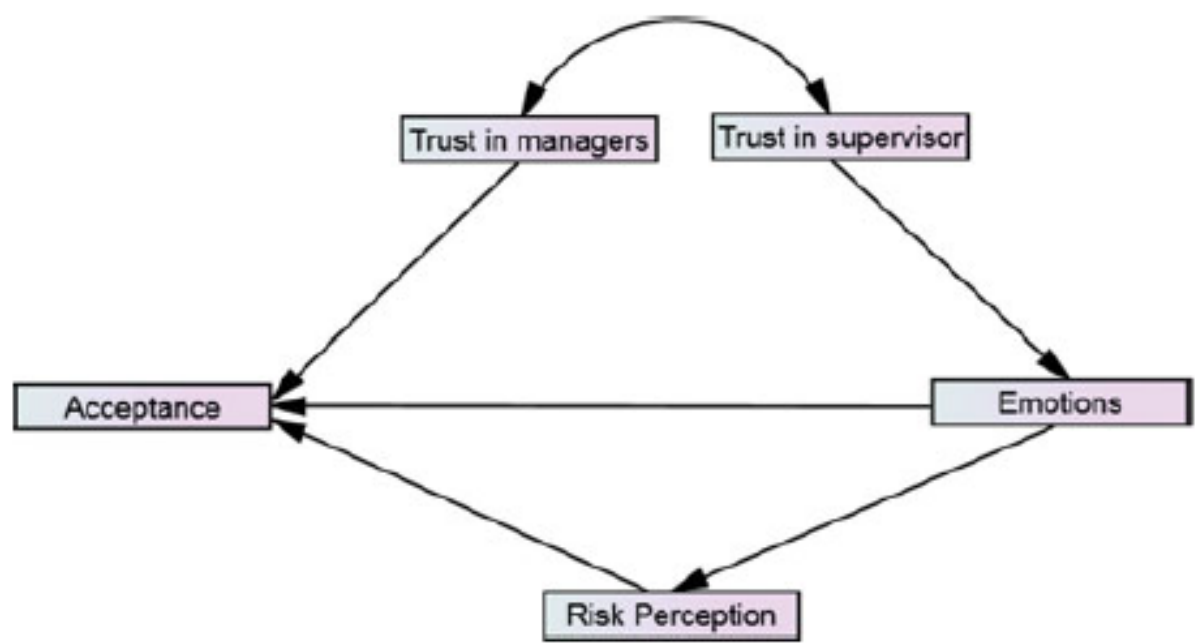

Figure 2. General model for occupational risk acceptance.

Several studies have found that risk perception influences risk acceptance, with an inverse relation (Ji et al. 2011; Bronfman et al. 2012; Huang et al. 2013). Also in the present study, a direct and negative influence of risk perception on risk acceptance was found (according to the results of Table S1 and Figure 2). These results were expected, as in occupational settings risk perception refers to a subjective assessment of the likelihood of experiencing an injury caused by the exposure to a risk factor (Rundmo 2000). Therefore, risks that are perceived as high are more likely to be unacceptable than risks that are perceived as low.

With respect to emotions, there seems to be general agreement that they are an important component that influences risk judgments (Rundmo 2000; Finucane et al. 2000; Quartz 2009; Mankad 2012), particularly due to their influence on risk perception, that is, judgments related to risk perception are guided and linked by emotions (affect) (Slovic 1987; Finucane et al. 2000; Slovic and Weber 2002; Dohle et al. 2010; Hu et al. 2013). The current study found both a direct and negative influence of emotions, specifically fear, on risk acceptance (according the results of Table S1 and Figure 2) and an indirect influence via risk perception (Figure 2). Therefore, the higher the fear related with a risk scenario, the lower the level of risk acceptance. That influence is higher than previously reported due also to the existence of a direct influence on risk acceptance observed in this study.

Trust in those who manage risk has also been associated, directly or indirectly, to risk acceptance (Siegrist 1999, 2000; Siegrist et al. 2000, 2005; Bronfman et al. 2008, 2009, 2012; Huang 2010; Huang et al. 2013). In the present work, despite the direct correlation identified among trust in managers, OSH practitioners and supervisors with risk acceptance (Table S1), the influence of each one differed. Trust in OSH practitioners did not contribute to the model; however, trust in managers presented a direct effect on the levels of risk acceptance, and trust in supervisors had an indirect effect via emotions $(p<.001)$. In fact, managers and supervisors are important people to the companies' safety. Managers establish policies and procedures to facilitate policy implementation, which in turn are executed by supervisors in each work group (Reese 2012). As workers' trust is based on interpretations of policies and procedures that exist within the organization and on the interactions among colleagues and leaders (Burke et al. 2007), if they do not trust in the managers and supervisors, they will be more likely to not follow it and to accept the risk. Furthermore, the influence of managers and supervisors is different, most likely because supervisors are close to workers and able to influence their levels of fear in relation to dangerous situations. For scenario SA1, the model with the best fit indices also presented an 
effect of trust in managers on emotions. For SA3, beyond the relations verified in the SA1 model, a significant effect of trust in managers on risk perception was identified $(p<.001)$. Furthermore, trust in supervisors was related to trust in managers $(p<.001)$. This may be related to their functions. Moreover, in some cases, the manager and the supervisor was the same person.

Previous studies on hazardous technologies and activities have found a strong relation between risk acceptance and benefit perception (Bronfman et al. 2009; Wallquist et al. 2012; Huang et al. 2013). In the current study, benefits influenced risk acceptance levels for only three scenarios. The scenarios SB3 and SB5 presented an effect of the BPE3 on risk acceptance and emotions. For SB4, beyond the effect of BPE3, BPE2 influenced risk perception and was related to BPE3. These results suggest that the effect of benefit perception is dependent on the mode of injury in the analysis and the scenario created. The effect of benefits was identified only for MSDs scenarios with low severity. When the severity was considered to be high, benefits did not influence risk acceptance. Furthermore, only benefits for employers were identified as having influence. Therefore, such results showed that for occupational accidents benefits do not play so important role in the risk acceptance level as in major hazards.

Influence of the Safety Climate on Risk Acceptance

Several authors have posited that culture influences risk judgments (Kouabenan 1998; Bickerstaff 2004; Tingley et al. 2010; Remoundou et al. 2014). In this context, cultural beliefs that are rooted in the group can define the level of risk that is considered acceptable and tolerable for that social group (Kouabenan 2009). However, the implications of culture and context on risk acceptance level for occupational settings are not well described or explored. Thus, an analysis of the influence of safety climate on risk acceptance, as an indicator of safety culture (as indicated by Flin et al. 2000; Tharaldsen et al. 2008; Høivik et al. 2009), was performed in this study. The correlations among the risk acceptance scenarios and the safety climate as well as the scales used to measure safety climate at the different levels are presented in Table S3 (SI).

For the total safety climate, only six scenarios (ASA2-ASA4, ASB4, and ASC) presented negative and significant correlations with risk acceptance. However, the influence of safety climate on risk acceptance was expected to be stronger. Therefore, considering that the differences in the three scales used to measure safety climate (organizational, group, and individual) may have a different relation to the risk acceptance evaluation, an analysis for each hierarchical level was performed.

The individual safety climate level was most related to risk acceptance. It was only not correlated with scenarios ASB2, ASB3, and ASB4 (all MSDs scenarios). These results can be due to the items included in the scale, which were related with workers' commitment to safety, including items about workers' attitudes/behaviors and to safety prioritization. In fact, it is expected that when an individual works within a group that presents high levels of safety climate, he/she can be more able to comply with company policies and procedures and also be more sensitive to safety issues. In those cases it is expected higher safe behaviors/attitudes due to a low risk acceptance level. This relationship, between safety climate and workers' safety behaviors, was already identified in previous studies (Rundmo 2000; Johnson 2007; Lu and Yang 2011; Fugas et al. 2012; Tholén et al. 2013). Furthemore, safety climate can also have influence on workers' risk perception levels, as previously observed (Rundmo, 2000; Huang et al., 2007; Tharandsen et al., 2008). This correlation was observed in this study, where risk perception was found to be correlated with individual level of safety climate ( $r<.318$, except ASB3-ASB5 and ASC). In view 
of this, in groups with high levels of safety climate, low risk acceptance levels, better workers' safety commitment and high levels of risk perception are expected. However, it is important to note that the relation between safety climate and risk acceptance was not so strong for organizational and group levels. At these levels considerations to managers and supervisors were analyzed; nevertheless, these scales were not found to directly influence workers' risk acceptance levels. Group features, particularly co-workers' norms can explain these results, as it has been related with safety climate differences among workgroups (Glendon et al. 2006; Brondino et al. 2012; Fugas et al. 2012). In fact, co-workers provide information to other workers and can influence safety behavior (Brondino et al. 2012), which may have greater importance than supervisor and manager in the risk acceptance level in this study.

The results previously presented do not indicate that the other levels in the analysis (organizational and group levels) do not explain variations in the level of risk acceptance. They can have an indirectly influence on risk acceptance. Shown in Table S4 (see the SI) are the correlations between trust and safety climate. Specifically, organizational and group levels were correlated with trust, which consequently influenced risk acceptance indirectly. These results emphasize the importance of trust on risk management as suggested by Luria (2010) and by Jeffcott et al. (2006). Trust on managers and supervisors can enable and enhance cooperation and communication, having a positive impact on safety climate (and safety culture) (Jeffcott et al. 2006). In fact, when supervisors and managers create a relationship of trust with workers, conditions to a safe working environment are improved, because workers believe in the information and procedures given to them, giving more importance to safety, and consequently, leading to a high safety climate levels (Luria 2010). For the individual scale no relationship with trust was found. These results indicate that the features of group, as co-workers norms, are able to have a direct influence on risk acceptance and managers and supervisors have an indirect influence, particularly influencing trust. In this context, these results show that culture creates (measured by safety climate) the context for risk acceptance, as previously determined by Kouabenan (2009).

\section{Values to Consider in Risk Acceptance Criteria}

In the current work, three important values for risk acceptance were analyzed (Roeser 2006; Huijts et al. 2012), as follows: equity, equality, and justice. Previous studies have related these values with risk perception (Slovic 1987; Slovic and Weber 2002), which influences risk acceptance. However, the current study intended not to analyze this relationship but to understand the most important values to consider for formulation of risk acceptance criteria.

The results showed that workers $(M=4.4, S D=1.0)$, employers $(M=4.5, S D=1.2)$, and supervisors $(M=4.7, S D=1.0)$ reported the need for a limit above which no individual should be exposed. When questioned about whether the need of the same upper risk threshold should be applied to all enterprises of the sector, the responses differed across the groups. Supervisors clearly agreed with the sentence $(M=5.0, S D=0.0)$, workers were slightly concordant $(M=3.7$, $S D=1.4)$, and employers were more indifferent $(M=2.9, S D=1.1)$. Finally, all reported that it is not fair to expose a worker to a very high risk, regardless of the benefits (Workers: $M=4.3, S D$ $=1.2$; Employers: $\mathrm{M}=4.8, \mathrm{SD}=0.6$; Supervisors $\mathrm{M}=4.8, \mathrm{SD}=0.7$ ). These results show that when the acceptance criteria are being defined, it is important to consider that no one should be exposed to very high risks, as previously argued by Aven (2007). However, in relation to determining whether the same criteria must be applied to all companies, the current results did not present a definite conclusion. Thus, and in accordance with the other results of the present 
study, risk acceptance criteria may be changed in accordance with companies' safety climate, which varies across companies or even workgroups (Clarke 2006; Brondino et al. 2013).

\section{CONCLUSIONS}

The current study analyzed the problem of risk acceptance in occupational settings. It allowed the characterization of the level of risk considered to be acceptable by workers in the furniture industries by analyzing not only the level of risk acceptance but also the variables that may influence it.

In general, higher risk levels were assessed as unacceptable. Furthermore, risk acceptance was influenced by the severity in high- and moderate-risk scenarios and by the accident frequency in low-risk scenarios. Thus, it was not surprising that the fatality scenario was considered to be unacceptable. Therefore, scenarios with low severity but high frequency were considered as unacceptable and when severity of consequences increases the influence of frequency appears to disappear and judgments about risk acceptance are dependent of severity level. In addition, differences across mode of injuries were identified when severity was high, where body cuts were seen as more negative than MSDs. When severity was lower, workers tended to share similar judgments about risk acceptance.

The general model obtained presents some differences from previous studies in other areas. It showed that people's responses to moderate and lower risks differed from those to major risks. The study also verified that emotions influence risk perception and directly affect risk acceptance. The influence of trust also differed. The present study verified a direct effect of trust in managers on risk acceptance level and an indirect influence, via emotions, of trust in supervisors. The influence of trust in managers on risk perception was verified for only a few scenarios. In relation to benefits, the study showed a little effect of this factor on the level of risk acceptance. Only employer benefits influenced risk acceptance for a few scenarios, particularly MSDs scenarios with low severity. On the other hand, the direct effect of risk perception on risk acceptance was predictable. Considering the results obtained in the current study, it is important to note that results may differ due to the scenarios utilized, particularly in a model that explains risk acceptance.

Another important finding of the present study is the significant correlation between safety climate and risk acceptance, risk perception, and trust. This result shows that risk acceptance may differ across different work contexts.

Finally, some important moral values should be considered in risk acceptance criteria formulation. Such formulation should consider equity because the respondents identified the need for a limit above which no individual should be exposed and justice because it was considered unfair for a worker to be exposed to a very high risk, regardless of the benefits.

These results provide insights for risk managers, mainly in terms of the risk assessment process. The findings may aid in defining the risk acceptance criteria to include in risk assessment methodologies and defining some strategies to reduce risks, particularly to change unsafe behavior.

\section{REFERENCES}

1. Aven T. 2007. On the ethical justification for the use of risk acceptance criteria. Risk Anal 27(2):303-12 
2. Bickerstaff K. 2004. Risk perception research: Socio-cultural perspectives on the public experience of air pollution. Environ Internat 30(6):827-40

3. Boholm A. 1998. Comparative studies of risk perception: A review of twenty years of research. J Risk Res 1(2):135-63

4. Brondino M, Silva SA, and Pasini M. 2012. Multilevel approach to organizational and group safety climate and safety performance: Co-workers as the missing link. Safety Sci 50(9):184756

5. Brondino M, Pasini M, and Silva SCA. 2013. Development and validation of an integrated organizational safety climate questionnaire with multilevel confirmatory factor analysis. Qual Quant 47(4):2191-23

6. Bronfman NC, Vázquez EL, Gutiérrez VV, et al. 2008. Trust, acceptance and knowledge of technological and environmental hazards in Chile. J Risk Res 11(6):755-73

7. Bronfman NC, Vázquez EL, and Dorantes G. 2009. An empirical study for the direct and indirect links between trust in regulatory institutions and acceptability of hazards. Safety Sci 47(5):686-92

8. Bronfman NC, Jiménez RB, Arévalo PC, et al. 2012. Understanding social acceptance of electricity generation sources. Energ Policy 46:246-52

9. Burke CS, Sims DE, Lazzara EH, et al. 2007. Trust in leadership: A multi-level review and integration. Leadership Quart 18(6):606-32

10. Cameron I and Raman R. 2005. Process Systems Risk Management. Elsevier, San Diego, USA

11. Clarke S. 2006. Contrasting perceptual, attitudinal and dispositional approaches to accident involvement in the workplace. Safety Sci 44(6):537-50

12. Dohle S, Keller C, and Siegrist M. 2010. Examining the relationship between affect and implicit associations: implications for risk perception. Risk Anal 30(7):1116-28

13. Eurostat. 2012. European Statistics on Accidents at Work (ESAW)-Summary Methodology. 2012 edit. Publications Office of the European Union. Luxemburg

14. Finucane $M L$, Alhakami A, Slovic $P$, et al. 2000. The affect heuristic in judgments of risks and benefits. J Behav Decis Making 13:1-17

15. Flin R, Mearns K, O'Connor P, et al. 2000. Measuring safety climate: Identifying the common features. Safety Sci 34(1-3):177-92

16. Fugas CS, Silva SA, and Meliá JL. 2012. Another look at safety climate and safety behavior: Deepening the cognitive and social mediator mechanisms. Accid Anal Prev 45:468-77

17. Glendon Al, Clarke SG, and Mckenna EF. 2006. Human Safety and Risk Management, 2nd edit. Taylor and Francis Group, Boca Raton, FL, USA

18. Harms-Ringdahl L. 2001. Safety Analysis: Principles and Practice in Occupational Safety, 2nd edit. Taylor and Francis Group, Boca Raton, FL, USA 
19. Høivik D, Tharaldsen JE, Baste V, et al. 2009. What is most important for safety climate: The company belonging or the local working environment?-A study from the Norwegian offshore industry. Safety Sci 47(10):1324-31

20. Hu T-Y, Xie X, and Li J. 2013. Negative or positive? The effect of emotion and mood on risky driving. Transport Res F-Traf 6:29-40

21. Huang L, Duan B, Bi J., et al. 2010. Analysis of determining factors of the public's risk acceptance level in China. Hum Ecol Risk Assess 16:365-79

22. Huang L, Ban J, Sun K, et al. 2013. The influence of public perception on risk acceptance of the chemical industry and the assistance for risk communication. Safety Sci 51(1):232-40

23. Huang $\mathrm{Y}-\mathrm{H}$, Chen J-C, DeArmond S, et al. 2007. Roles of safety climate and shift work on perceived injury risk: A multi-level analysis. Accident Anal Prev 39(6):1088-96

24. Huijts NMA, Molina EJE, and Steg L. 2012. Psychological factors influencing sustainable energy technology acceptance: A review-based comprehensive framework. Renew Sust Energ Rev 16(1):525-31

25. ISO 31000:2009. 2009. Risk Management-Principles and Guidelines. International Organization for Standardization, Geneva, Switzerland

26. Jeffcott S, Pidgeon N, Weyman A, et al. 2006. Risk, Trust, and safety culture in U.K. train operating companies. Risk Anal 26(5):1105-21

27. Ji M, You X, Lan J, et al. 2011. The impact of risk tolerance, risk perception and hazardous attitude on safety operation among airline pilots in China. Safety Sci 49(10):1412-20

28. Johnson SE. 2007. The predictive validity of safety climate. J Saf Res 38(5):511-21

29. Kjellén U and Sklet S. 1995. Integrating analyses of the risk of occupational accidents into the design process. Part I: A review of types of acceptance criteria and risk analysis methods. Safety Sci 18(3):215-27

30. Kline RB. 2010. Principles and Practice Of Structural Equation Modelling, 3rd edit. Guilford Press, New York, NY, USA

31. Kouabenan DR. 1998. Beliefs and the perception of risks and accidents. Risk Anal $18(3): 243-52$

32. Kouabenan DR. 2009. Role of beliefs in accident and risk analysis and prevention. Safety Sci 47(6):767-76

33. Lu C-S and Yang C-S. 2011. Safety climate and safety behavior in the passenger ferry context. Accid Anal Prev 43(1):329-41

34. Luria, G. 2010. The social aspects of safety management: Trust and safety climate. Accid Anal Prev 42:1288-95

35. Mankad A. 2012. Decentralised water systems: Emotional influences on resource decision making. Environ Internat 44(1):128-40

36. Miguel ASSR. 2012. Manual de Higiene e Segurança do Trabalho, 12th edit. Porto Editora, Portugal 
37. Muthén OB. 1994. Multilevel covariance structure analysis. Sociol Method Res 22(3):37698

38. Quartz SR. 2009. Reason, emotion and decision-making: Risk and reward computation with feeling. Trends Cogn Sci 13(5):209-15

39. Reese CD. 2012. Accident/Incident Prevention Techniques, 2nd edit. Taylor and Francis Group, New York, NY, USA

40. Reise SP, Ventura J, Nuechterlein KH, et al. 2005. An illustration of multilevel factor analysis. J Pers Assess 84(2):126-36

41. Remoundou K, Brennan M, Hart A, et al. 2014. Pesticide risk perceptions, knowledge, and attitudes of operators, workers, and residents: A review of the literature. Hum Ecol Risk Assess 20:1113-38

42. Rodrigues MA, Arezes $P$, and Leão CP. 2013. Development of a multilevel safety climate measure for furniture industries. In: Arezes $\mathrm{P}$, Baptista JS, Barroso M, et al. (eds), Occupational Safety and Hygiene, pp 515-9

43. Rodrigues MA, Arezes P, and Leão CP. 2014. Development of an instrument to analyze the occupational risk acceptance. In: Steenbergen RDJM, van Gelder PHAJM, Miraglia S, et al. (eds), Safety, Reliability and Risk Analysis: Beyond the Horizon, pp 1573-8

44. Rodrigues MA, Arezes P, and Leão CP. Multilevel model of safety climate for furniture industries. Work.

45. Roeser S. 2006. The role of emotions in judging the moral acceptability of risks. Safety Sci 44(8):689-700

46. Rundmo T. 2000. Safety climate, attitudes and risk perception in Norsk Hydro. Safety Sci 34(1-3):47-59

47. Rundmo T, Nordfjærn T, Iversen $\mathrm{HH}$, et al. 2011. The role of risk perception and other riskrelated judgements in transportation mode use. Safety Sci 49(2):226-35

48. Siegrist M. 1999. A causal model explaining the perception and acceptance of gene technology. J Appl Soc Psychol 29:2093-106

49. Siegrist M. 2000. The influence of trust and perceptions of risks and benefits on the acceptance of gene technology. Risk Anal 20(2):195-203

50. Siegrist M, Cvetkovich G, and Roth C. 2000. Salient value similarity, social trust, and risk/benefit perception. Risk Anal 20(3): 353-62

51. Siegrist M, Gutscher $H$, and Earle TC. 2005. Perception of risk: The influence of general trust, and general confidence. J Risk Res 8(2):145-56

52. Slovic P. 1987. Perception of risk. Science 236:280-5

53. Slovic $P$ and Weber EU. 2002. Perception of risk posed by extreme events. Proceedings of Risk Management strategies in an Uncertain World, Palisades, New York, April 12-13

54. Tharaldsen JE, Olsen E, and Rundmo T. 2008. A longitudinal study of safety climate on the Norwegian continental shelf. Safety Sci 46(3):427-39 
55. Tholén SL, Pousette A, and Torner M. 2013. Causal relations between psychosocial conditions, safety climate and safety behaviour-A multi-level investigation. Safety Sci 55:62-9

56. Tingley D, Ásmundsson J, Borodzicz E, et al. 2010. Risk identification and perception in the fisheries sector: Comparisons between the Faroes, Greece, Iceland and UK. Mar Policy 34(6):1249-60

57. van de Vijver FJR and Poortinga YH. 2002. Structural equivalence in multilevel research. J Cross Cult Psychol 33(2):141-56

58. Wallquist L, Visschers VHM, Dohle S, et al. 2012. The role of convictions and trust for public protest potential in the case of carbon dioxide capture and storage (CCS). Hum Ecol Risk Assess 18:919-32

59. Wogalter MS, Young SL, Brelsford JW, et al. 1999. The relative contributions of injury severity and likelihood information on hazard-risk judgments and warning compliance. J Risk Res 30(3):151-62

60. Young L-H, Kuob H-W, and Chiangc C-F. 2015. Environmental health risk perception of a nationwide sample of taiwan college students majoring in engineering and health sciences. Hum Ecol Risk Assess 21(2):307-26

61. Zohar D and Luria G. 2005. A multilevel model of safety climate: Cross-level relationships between organization and group-level climates. J Appl Soc Psychol 90(4):616-28 